\title{
Optimal Operation and Real-Time Monitoring of 300MW Boiler Based on Excess Air Coefficient
}

\author{
Jia Mengshuo \\ Department of Electrical engineering and its automation \\ North China Electric Power University \\ Baoding,China \\ e-mail: jiam5588@163.com
}

\begin{abstract}
At present, 300MW generating unit serves as the main facility in power plant in China. This paper analyzes the optimal operation of $300 \mathrm{MW}$ generating unit boiler. By constructing the models of waste heat loss q_2, air non complete combustion heat loss $q \_3$, solid non complete combustion heat loss $q_{-} 4$, using polynomial fitting, the best excess air coefficients at different load are calculated. Through the introducing of two model: heat loss q_5 and ash Physical loss q_6, we present the relationship between excess air coefficient and boiler efficiency by anti-balance method. After the analysis on the relationship between excess air coefficient and oxygen content, we put up with the real-time monitoring model of boiler efficiency. The computational example based on experiment data shows our method is effective and feasible.
\end{abstract}

Keywords-boiler efficiency; best excess air coefficient, optimal operation;300MW;real-time monitoring

\section{INTRODUCTION}

At present, take China for example, thermal power generationinstalled capacity occupies approximately $73 \%$ of total generated energy. As can be seen from this data, thermal power generation is the kind of generation that consumes the most energy. Thus thermal power generation is very important for China's energy saving in industrial field ${ }^{[1]}$. Therefore, studying on the optimal operation of boiler in thermal power generation is and urgent research.

This paper focus on the optimal operation of 300MW unit boiler, and solve four problems. First, determine the best excess air coefficient of boiler's operation. Second, the relationship between the efficiency of boiler and excess air coefficient is given. Third, we present the optimal operation method of the boiler. Fourth, we realize the real-time monitoring.

Excess air coefficient $\alpha$ is an important parameter in optimal operation. Gao uses smooth curve best approach with line to calculate the best excess air coefficient $\alpha^{[2]}$. Differed from their work, through higher order polynomial fit and experiment data, we build the model of waste heat loss $q_{2}$, air non complete combustion heat loss $q_{3}$, solid non complete combustion heat loss $q_{4}$. And by differentiation, we obtain the best excess air coefficient, which is changing as boiler load changing.
As for the relationship between the efficiency of boiler and excess air coefficient, Yan think the general method is recording the data by lots of experiments, and measuring the relationship between the efficiency of boiler and excess air coefficient ${ }^{[3]}$. More experiments is good for research. We introduce two model: heat loss $q_{5}$, ash physical loss $q_{6}$, and by using anti-balance method ${ }^{[4]}$, construct the model of boiler efficiency and obtain the relationship.

The optimal operation of the boiler involves plenty of parameters: excess air coefficient, the load, the fineness of pulverized coal, the tertiary air, the pressure of primary air and the mode of air distribution and so on ${ }^{[5]}$. We analyse the load, excess air coefficient, coal quality and the fineness of pulverized coal qualitatively.

In order to realize the real-time monitoring of the boiler efficiency, real-time monitoring equipment is necessary. At present most of boilers is equipped with oxygen contentdetection device at flue. By the relationship between excess air coefficient and oxygen content $^{[6]}$, we present the method of real-time monitoring of the boiler efficiency.

The paper is organized as follows. In the next section, some assumptions are given. In Section 3, the best excess air coefficient of boiler's operationis presented. Section 4 presents the relationship between the efficiency of boiler and excess air coefficient. In Section 5, optimal operationanalysis and real-time monitoring of the boileris made. The computational simulation is made in section 6 . Finally, we conclude our paper in section 7.

\section{ASSUMPTIONS}

- Boiler efficiency only associated with the given parameters.

- No autocorrelation between parameters (such as the change rate of load of the boiler does not have influence for boiler efficiency).

- Choice of pros and cons of controllable parameters of boiler is only related to boiler efficiency.

- Accumulation of fly ash in boiler would not affect boiler efficiency. 


\section{THE BEST EXCESS AIR COEFFICIENT}

\section{A. Waste heat loss}

Waste heat loss is biggest loss in boiler's operation. Normally this loss would occupies $4 \%$ to $8 \%$. Waste heat loss is mainly defined by two parameters: exhaust gas temperature and exhaust smoke volume. The higher the exhaust gas temperature and exhaust smoke volume are, the higher the exhaust smoke enthalpy is. The model of $q_{2}$ is as followed:

$$
\begin{aligned}
& Q_{2}=\left(h_{p y}-h_{l k}\right) \times\left(1-\frac{q_{4}}{100}\right)(1) \\
& q_{2}=\frac{Q_{2}}{Q_{r}} \times 100 \% \\
& h_{l k}=a V^{0} \times(c t)_{l k}(3)
\end{aligned}
$$

Where $h_{p y}$ is exhaust smoke enthalpy, $h_{l k}$ is cold air enthalpy, and $(c t)_{l k}$ isthe enthalpy of 1 cold air.

\section{B. Air non complete combustion heat loss}

Air non complete combustion heat loss is also called chemical non complete combustion heat loss. This kind of loss is caused by the residue of combustible gas in boiler. Air non complete combustion heat loss is mainly defined by the following parameters: the volatility of fuel, excess air coefficient in the furnace, burner's structure and layout and furnace temperature.

The model of $q_{3}$ is as followed.

$Q_{3}=\frac{V_{g y}}{100}\left(12636 C O+10789 H_{2}+35818 C_{4}+59079 C_{m} H_{m}\right)$ (4)

$q_{3}=\frac{Q_{3}}{Q_{r}} \times 100 \%$

i) $V_{g y}$ is the dry flue gas volume, which is from the noncomplete combustion of $1 \mathrm{~kg}$ ARB fuel. The dimension is $\mathrm{m}^{3} / \mathrm{kg}$.

ii) $\mathrm{CO}, \mathrm{H}_{2}, \mathrm{CH}_{4}$ and $\mathrm{C}_{m} \mathrm{H}_{m}$ are the volume component in dry flue gas. When it comes to solid fuel, $C O=0$.

iii) The value of is usually defined by the kind of fuel and the kind of combustion mode. Normally, $q_{3}=0$ when the boiler is pulverized coal fired boiler, and $q_{3}=0.5 \%$ when the boiler is fuel or gas fired boiler.

\section{Solid non complete combustion heat loss}

When solid fuel is burning in boiler, part of solid fuel particles would fall into the furnace bottom and become ash pit. This part of loss is called solid non complete combustion heat loss. Solid non complete combustion heat loss is defined by parameters: ashes loss and fly ash loss.

The model of $q_{4}$ is as followed.

$$
\begin{gathered}
Q_{4}=B \times a_{h z} \times C_{h z} \times(C \vartheta)_{h z}+D \times A^{y} C_{h f} \times(C \vartheta)_{f h}(6) \\
q_{4}=\frac{Q_{4}}{Q_{r}} \times 100 \%(7)
\end{gathered}
$$

i)is the main air low rate, $A^{y}$ is ash, is the average levels of consumption during the test. ii)is the rate of furnace bottom slag, $(C \vartheta)_{h z}$ is the enthalpy of ash theoretically. $(C \vartheta)_{f h}$ is the enthalpy of fly ash theoretically.

iii) $C_{h z}$ is the furnace bottom ash combustible, which can be fitted by polynomial fitting when the experiment data is given.

\section{The best excess air coefficient}

After the modeling of $q_{2}, q_{3}, q_{4}$, we obtain the equation:

$$
q_{2}+q_{3}+q_{4}=f(\alpha)(8)
$$

The best excess air coefficient is thethat make $q_{2}+q_{3}+q_{4}$ reach to the minimum value. Therefore, take the derivation of $f(\alpha)$.

$$
\frac{\partial f(\alpha)}{\partial \alpha}=\frac{\partial\left(q_{2}+q_{3}+q_{4}\right)}{\partial \alpha}=0
$$

Then we obtain the best excess air coefficient

\section{BOILER EFFICIENCY AND EXCESS AIR COEFFICIENT}

Through anti-balance method, the relationship between boiler efficiency and excess air coefficient can be presented.

$$
\eta_{g l}=q_{1}=\frac{Q_{1}}{Q_{r}} \times 100=\left[100-\left(q_{2}+q_{3}+q_{4}+q_{5}+q_{6}\right)\right] \%(10
$$

Where $\eta_{g l}$ is the boiler efficiency. In order to get the relationship between boiler efficiency and excess air coefficient, the model $q_{5}$ and $q_{6}$ must be given.

$q_{5}$ is heat loss. $q_{5}$ is caused by the heat dissipation of the operating boiler.

$$
\left\{\begin{array}{c}
q_{5, e d}=5.82\left(D_{e d}\right)^{-0.38} \\
q_{5=} q_{5, e d} \times \frac{D_{e d}}{D}
\end{array}\right.
$$

Where $q_{5, e d}$ is the heat loss that is in rated evaporative power and $q_{5}$ is in non-rated evaporative power. Likewise, $D_{e d}$ is the main air low rate that is in rated evaporative power and $D$ is in non-rated evaporative power.

$q_{6}$ is ash Physical loss. This kind of loss is in the slag of ash, fly ash and fallout.

$$
\begin{aligned}
& Q_{6}=a_{h z} \times \frac{A^{y}}{100}(c v)_{h z} \\
& q_{4}=\frac{Q_{4}}{Q_{r}} \times 100 \%
\end{aligned}
$$

Where $v$ is the temperature of ash. Usually $v=800^{\circ} \mathrm{C}^{[7]}$

After the building of this two models, the relationship between boiler efficiency and excess air coefficient can be obtained. Through the substitution of (2), (5), (7), (12) and 
(14) into (10), the relationship between boiler efficiency and excess air coefficient is clear.

\section{THE OPTIMAL OPERATION OF BOILER}

The optimal operation is determined by two aspects: the adjustment before operation and the real-time monitoring. As for the adjustment before operation, we analyse the load, excess air coefficient, coal quality and the fineness of pulverized coal qualitatively and quantitatively. But we focus on the real-time monitoring.

\section{A. Adjustment before operation}

In order to reach optimal operation, the adjustment before operation is very important

- As mentioned above, as the change of excess air coefficient, the boiler efficiency change and has the maximum value. Therefore we should adjust the excess air coefficient to the best excess air coefficient before operation. And the best excess air coefficient can be calculate from experiment data.

- The best excess air coefficient changes as the load changes. In other words, the best excess air coefficient is equal to the best load. Adjust the load before operation can obtain the best boiler efficiency $^{[8]}$.

- As for the coal quality, the morevolatile in the coal, the better ${ }^{[9]}$.

- The more homogeneous pulverized coal particle is, the better for the operation of the boiler $^{[10]}$.

\section{B. Real-time monitoring.}

With the help of oxygen contentdetection device at flue, we obtain the real-time oxygen content. Our model of boiler efficiency is based on excess air coefficient. Construct the model between excess air coefficient and oxygen content, then we can realize the real-time monitoring of the boiler efficiency, and can adjust the parameters of the boiler to realize the optimal operation.

$$
\alpha=\frac{V}{V^{0}}=\frac{V}{V^{0}-V_{g}}=\frac{1}{1-\frac{(\alpha-1) V^{0}}{\alpha V^{0}}}
$$

Hence, we get that:

$$
\begin{gathered}
(\alpha-1) V^{0}=\frac{V_{\mathrm{O}_{2}}-0.5 V_{\mathrm{CO}}}{0.21} \\
V_{N_{2}}^{0}=0.79 V^{0}+0.8 \frac{N_{a r}}{100}
\end{gathered}
$$

Based on the (16) and (17), we obtain (18):

$$
V_{N_{2}}=V_{N_{2}}^{0}+0.79(\alpha-1) V^{0}
$$

Through the substitution of (16), (17) and (18) into (15), the (19) is as followed:

$$
\alpha=\frac{1}{1-\frac{0.79\left(V_{\mathrm{O}_{2}}-0.5 V_{C O}\right)}{0.21 V_{N_{2}}}}
$$

By using the definition formula of and, which are as followed, we get the (24):

$$
\begin{array}{r}
O_{2}=\frac{V_{O_{2}}}{V_{g y}} \times 100 \%(20) \\
N_{2}=\frac{V_{N_{2}}}{V_{g y}} \times 100 \% \quad(21) \\
C O=\frac{V_{C O}}{V_{g y}} \times 100 \%(22) \\
R O_{2}+O_{2}+N_{2}+\mathrm{CO}=100 \\
\alpha=\frac{R O_{2}^{M a x}}{R O_{2}} \approx \frac{21}{(1+\beta) R O_{2}}
\end{array}
$$

According to the complete combustion equation $(1+\beta) \mathrm{RO}_{2}=21-\mathrm{O}_{2}$, the relationshipbetween excess air coefficient and oxygen content is finally obtained:

$$
\alpha \approx \frac{21}{21-O_{2}}
$$

By monitoring the oxygen content and (25), we can realize the real-time monitoring of excess air coefficient. And (10) presents the relationship between the excess air coefficient and boiler efficiency, thus the real-time monitoring of boiler efficiency is realized.

\section{COMPUTATIONAL EXAMPLES AND ANALYSIS}

The experiment data is showed in Table. 1 and Table.2:

TABLE 1. Experiment Data I

\begin{tabular}{c|c}
\hline \hline$\alpha$ & $C_{f h}$ \\
\hline 1.1 & 5.90 \\
1.15 & 5.10 \\
1.2 & 4.75 \\
1.25 & 4.6 \\
1.3 & 4.55 \\
1.35 & 4.50 \\
1.4 & 4.45 \\
1.45 & 4.43 \\
1.5 & 4.50 \\
\hline \hline
\end{tabular}

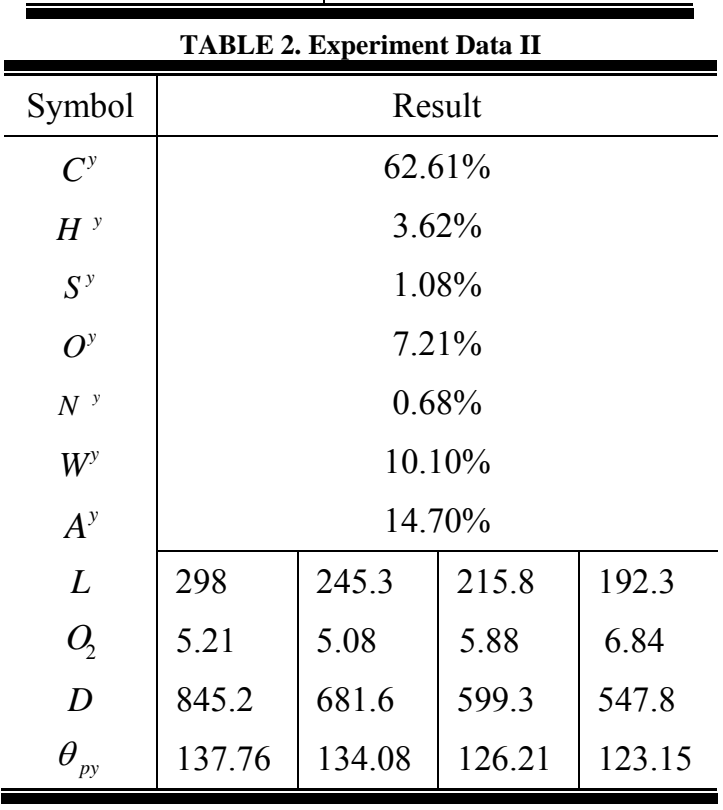


Step 1: (Polynomial fitting of ) By using the data from Table.1, we build three-order polynomial to fit. And the fitting function is as followed:

$$
C_{f h}=-68.0808 \times \alpha^{3}+282.2292 \times \alpha^{2}-389.3885 \times \alpha+183.2855
$$

Step 2: (Calculate the best excess air coefficient) Through the substitution of $C_{f h}$ into (8), and by using (9). We present thefigure in Fig. 1 and the best excess air coefficient in Table. 3

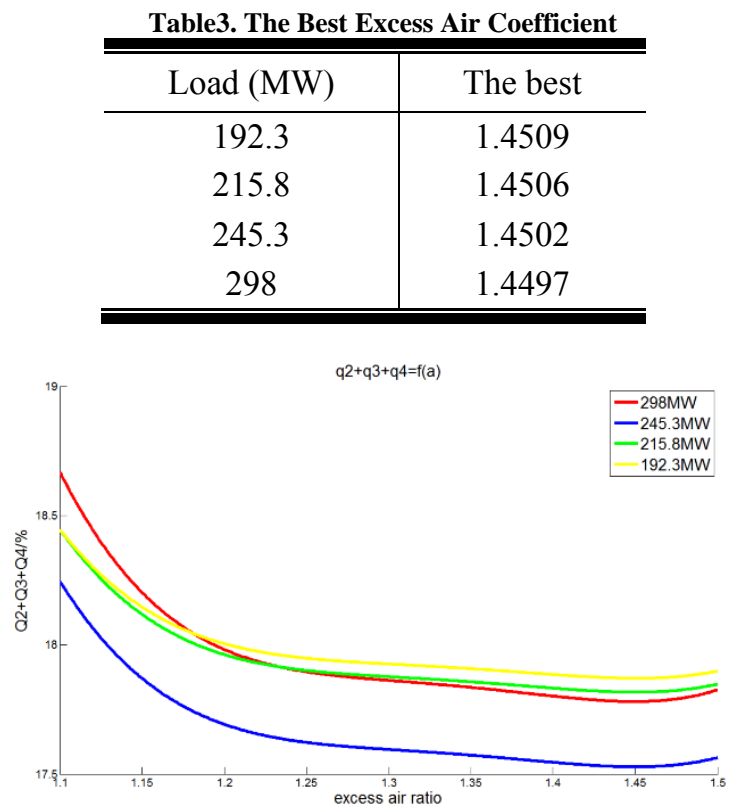

Figure 1. The best excess air coefficient

Step 3: (Boiler efficiency and excess air coefficient) Through the substitution of (2), (5), (7), (12) and (14) into (10), the relationship between boiler efficiency and excess air coefficient is presented in Table.4.

\begin{tabular}{c|l}
\multicolumn{2}{r}{ TABLE 4. Boiler Efficiency and Excess Air Coefficient } \\
\hline \hline Load & \\
\hline 298 & $\eta_{g l}=40.1838 \times \alpha^{3}-166.5822 \times \alpha^{2}+229.8315 \times \alpha-24.3201$ \\
245.3 & $\eta_{g l}=40.0609 \times \alpha^{3}-166.0731 \times \alpha^{2}+229.1290 \times \alpha-24.2486$ \\
215.8 & $\eta_{g l}=39.7983 \times \alpha^{3}-164.9841 \times \alpha^{2}+227.6266 \times \alpha-24.0958$ \\
192.3 & $\eta_{g l}=39.6962 \times \alpha^{3}-164.5607 \times \alpha^{2}+227.0424 \times \alpha-24.0364$ \\
\hline \hline
\end{tabular}

Step 4: (Real-time monitoring) We obtain the relationship between boiler efficiency and excess air coefficient above. By the substitutionof (25), we can get the relationship between boiler efficiency and the oxygen content to realize real-time monitoring. With the help of the monitoring, we can adjust the parameters when the boiler is operating and reach to optimal operation.

\section{CONCLUSIONS}

In this paper, we build the model of waste heat loss $q_{2}$, air non complete combustion heat loss $q_{3}$, solid non complete combustion heat loss $q_{4}$, heat loss $q_{5}$ and ash Physical loss $q_{6}$. And calculate the best excess air coefficient at different load and present the relationship between boiler efficiency and excess air coefficient. Qualitatively analyse the load, excess air coefficient, coal quality and the fineness of pulverized coal in optimal operation. And finally realize the real-time monitoring of boiler efficiency by oxygen content in flue, which can enable the operators to adjust the parameters when the boiler is operating in order to realize optimal operation.

\section{ACKNOWLEDGMENT}

First and foremost, I would like to show my deepest gratitude to my supervisor, Dr.Wangchunbo, a respectable, responsible and resourceful scholar, who has provided me with valuable guidance in every stage of the writing of thisthesis. Without his enlightening instruction, impressive kindness and patience, Icould not have completed my thesis. His keen and vigorous academic observationenlightens me not only in this thesis but also in my future study.

Last but not least, I'd like to thank all my friends, especially my three lovely roommates, for their encouragement and support.

\section{REFERENCES}

[1] Yang. Y.P, Yang. Z.P, Xu. G. andWang. N.L, "Situation and Prospect of Energy Consumption for China's Thermal Power Generation,'Proceedings of the CSEE,vol.33,pp.1-11, Aug 2013.

[2] Gao. L.X, Yuan. L.J, Zhou. Z.NandLi. C, "New Way to Ascertain Optimal Excess Air Coefficient,"Coal Mine machinery,vol.30,pp.31-32, Feb 2009.

[3] Yan. S.L, Zhang. B, Wu. H.Y andWu. Q.Y, "Study on Optimal Excess Air Coefficient for Power Plant Boilers,"Power equipment,vol.4,pp.237-240, Oct 2009.

[4] Guo. J.L, Yao. L.Q, Yang. H.SandZhang. S.F, "Influence of Pipe Efficiency on Calculating Coal Consumption by Anti-balance method," Thermal Power generation,vol.38,pp.58-60, 2009.

[5] Li. Y.H, Chen. H.Wand Meng. F.J, “An Experimental Study on Optimal Combustion Control for A Boiler of 300MW,"Proceedings of the CSEE,vol.24,pp.216-220, Jan 2004.

[6] Zhou. Q.T, "Boiler Principle,"China Electric Power Press,vol.24,pp.216-220, Aug 2013.

[7] Zhang. J.L, Li. Y.J, Wang. Q.G, Deng. J, Xu. Y.X and Sheng. H.Z, "Parameter on Waste Incinerator Fly Ash Vitrification," Journal of Combustion Science and Technology, vol.18, pp.186-191, April 2012

[8] Zhang. B, "The effect on net coal consumption rate of coal-fired boiler under different running parameters," North China Electric Power University, Dec 2009.

[9] Bi. Y.SandChen. G.H, "Low Volatile Coals with a W Flame Boiler," Thermal Power generation,vol.34,pp.7-10,July 2005.

[10] Wei. L, Li. R.D, L. A.M, L. Y.J, and Jiang. X.M, "Thermogravimetric analysis on the pyrolysis characteristics of Pulverized coal," Proceedings of the CSEE, vol.28, pp.53-57, Sep 2008 